\title{
Halliburton Sperry-Sun DOE High Temperature LWD Project
}

Final Report

Ronald L. Spross, Author

March 15, 2005

DOE Award \#DE-AC26-97FT34175

Halliburton Energy Services 3000 N. Sam Houston Pkwy. E. Houston, TX 77032 
THIS PAGE DELIBERATELY LEFT BLANK 


\section{Disclaimer}

This report was prepared as an account of work sponsored by an agency of the United States Government. Neither the United States Government nor any agency thereof, nor any of their employees, makes any warranty, express or implied, or assumes any legal liability or responsibility for the accuracy, completeness, or usefulness of any information, apparatus, product, or process disclosed, or represents that its use would not infringe privately owned rights. Reference herein to any specific commercial product, process, or service by trade name, trademark, manufacturer, or otherwise does not necessarily constitute or imply its endorsement, recommendation, or favoring by the United States Government or any agency thereof. The views and opinions of authors expressed herein do not necessarily state or reflect those of the United States Government or any agency thereof.

Available to the public from the National Technical Information Service, U.S. Department of Commerce, 5285 Port Royal Road, Springfield, VA 22161; phone orders accepted at (703) 487-4650. 
THIS PAGE DELIBERATELY LEFT BLANK 


\section{Abstract}

The objective of this project was to build a high temperature, costeffective, logging while drilling (HT-LWD) system with the ability to operate at $175^{\circ} \mathrm{C}$ with more than 100 hours mean time between failures (MTBF). Such a commercial real-time formation evaluation (FE) system would help operators to drill and produce hydrocarbon resources from moderately deep, hot reservoirs which otherwise might be uneconomic to drill.

The project plan was to combine the existing Sperry-Sun high temperature directional and gamma logging system with lower temperature FE sensors which were upgraded to higher temperature operation as part of the project. The project was to be completed in two phases. Phase I included the development of the HT system, building two complete systems, demonstrating operational capability at $175^{\circ} \mathrm{C}$ and survivability at $200^{\circ} \mathrm{C}$ in the laboratory, and successfully testing the system in two low temperature field tests. Phase II was to test the system in a well with a bottom hole temperature of $175^{\circ} \mathrm{C}$.

The high temperature FE sensors developed as part of this project include gamma ray (DGR), resistivity (EWR-Phase 4), neutron (CTN), and density (SLD). The existing high temperature pulser and telemetry system was upgraded to accommodate the data and bandwidth requirements of the additional sensors. Environmental and lifetime testing of system components and modules indicates that system life and reliability goals will be substantially exceeded. The system has performed well in domestic and international high temperature wells (to $175^{\circ} \mathrm{C}$ ). In addition to the sensor modules specified in the project contract, Sperry has now upgraded other system components to higher temperature as well. These include a LWD sonic sensor (BAT), pressure while drilling sensor (PWD), and a more powerful central system controller (CIM). 
THIS PAGE DELIBERATELY LEFT BLANK 


\section{Table of Contents}

DISCLAIMER

ABSTRACT

$\begin{array}{ll}\text { TABLE OF CONTENTS } & 7\end{array}$

EXECUTIVE SUMMARY

Description of Project Objectives and Work Plan

Summary of Accomplishments

Conclusions and Recommendations

\section{PROJECT DESCRIPTION}

Project Objectives

Project Background

System Description

Project Tasks and Accomplishments

Field Test Results

Economic and Market Considerations - the Need for LWD

Conclusions and Recommendations

Acronyms in the Report Body

Figure 1: Log Example

Figure 2: Pulser/Generator/Telemetry/GM/TM

Figure 3: EWR Slim Phase 4 Tool

Figure 4: CTN

Figure 5: Stabilized LithoDensity Tool 
THIS PAGE DELIBERATELY LEFT BLANK 


\section{Executive Summary}

\section{Description of Project Objectives and Work Plan}

The overall objective of this project was to build a high temperature, costeffective, logging while drilling (HT-LWD ${ }^{*}$ ) system with the ability to operate at $175^{\circ} \mathrm{C}$ with more than 100 hours mean time between failure (MTBF). Such a commercial real-time formation evaluation (FE) system would help operators to drill and produce hydrocarbon resources from deep, hot reservoirs, including Mobile Bay in the GOM, the western GOM, and the deep Austin Chalk, which otherwise might be uneconomic to drill. The project plan was to leverage the existing systems of Sperry-Sun - the HT Solar $175^{\dagger}$ tool and lower temperature FE sensors including the resistivity and neutron porosity sensors - in the development of the HT system.

The project was to be completed in two phases. Phase I included the development of the HT system, building two complete systems, demonstrating operational capability at $175^{\circ} \mathrm{C}$ and survivability at $200^{\circ} \mathrm{C}$ in the laboratory, and successfully testing the system in two low temperature field tests. Phase II was to test the system in a well with a bottom hole temperature of $175^{\circ} \mathrm{C}$.

The original HT-LWD system concept did not include a density sensor, but the goals of the project were later modified at the request of Sperry-Sun to include a density sensor. Consequently, the HT-LWD system has the full complement of services for basic FE.

With DOE support, Sperry-Sun has developed and successfully field tested each of the key HT-LWD sensors. Sperry-Sun also independently developed certain complementary modules in parallel to and/or subsequent to the DOE project, including a HT central interface module (HT-CIM). As a result, Sperry-Sun is currently able to field a complete HT-LWD system with capabilities meeting or exceeding those envisioned in the original proposal. This system is also able to easily accept additional sensors and services in the future.

\footnotetext{
A table of acronyms is in the Appendix of this report.

${ }^{\dagger}$ Solar 175 is a registered trademark of Halliburton Energy Services, Inc.
} 


\section{Summary of Accomplishments} following:

Among the more significant accomplishments of the project are the

1. FE sensors for gamma ray $\left(D G R^{\ddagger}\right)$, resistivity (EWR-Phase $4^{\ddagger}$ ), neutron $\left(\mathrm{CTN}^{\ddagger}\right)$, and density $\left(\mathrm{SLD}^{\ddagger}\right)$ logging were developed, lab tested to $175^{\circ} \mathrm{C}$ operating, $200^{\circ} \mathrm{C}$ survival, and field tested.

2. Pulser and telemetry systems were upgraded to HT specifications and successfully tested in the lab and field.

3. System field testing has demonstrated the system's performance per requirements at temperatures from $150^{\circ} \mathrm{C}$ to $175^{\circ} \mathrm{C}$.

4. Component and module field testing has indicated that system life goals will be substantially exceeded. System data from the field are consistent with this but are as yet too limited to provide a firm validation.

5. Additional tool infrastructure / data management modules were developed and tested to $175 / 200^{\circ} \mathrm{C}$.

\section{Conclusions and Recommendations}

1. The HT-LWD project goals were met in that all sensors were developed, and lifetime and field testing were successful.

2. The addition of the HT controller module has enabled inclusion of other sensors in the HT-LWD system, including sonic and pressure while drilling sensors. ${ }^{\S}$

3. Although a working HT-LWD system has been demonstrated at $175^{\circ} \mathrm{C}$, higher temperature operation (e.g. $200 \mathrm{C}+$ ) may be needed in the near future to seriously address deeper, hotter, harsher gas resources and the geothermal market.

4. Other technologies such as silicon on insulator (SOI) and nonscintillating particle detection technologies (e.g., GM tubes) are possible paths to develop the capability for entering these higher temperature markets.

5. Halliburton is monitoring emerging technologies, as well as pursuing internal developments, to meet these future needs.

\footnotetext{
Inc.

$\S$ The HT upgrades of the CIM, sonic, and pressure sensors while drilling tools were all done at Sperry-Sun's expense and were outside the scope of this project.
}

‡ DGR, EWR-Phase 4, CTN, and SLD are trademarks of Halliburton Energy Services, 


\section{Project Description}

\section{Project Objectives}

Sperry-Sun Drilling Services understands that DOE's objective is to increase the available gas resources and to assist industry in meeting natural gas production requirements of the nation. Significant deposits of this resource are believed to be in deep, HT gas prospects such as the deep Austin Chalk and Western Gulf of Mexico. Accordingly, the objective of this project was to develop a high temperature, cost effective, logging while drilling (HT-LWD) system to evaluate and produce these prospects. Logging while drilling has been a key element in the drilling of horizontal and multilateral wells. HT LWD tools will be an enabling technology that will bring these drilling methods to deeper, hotter formations.

Initially the project was envisioned for two phases. In Phase I, two logging systems would be developed and tested in the laboratory environment to $175^{\circ} \mathrm{C}$. Phase I would be completed with a system test in a low temperature well $\left(<150^{\circ} \mathrm{C}\right)$. In Phase II, the system would be run in commercial HT wells.

Sperry-Sun Drilling Services began the project with a HT logging capability in the form of the already-commercial Solar 175 Tool. This system provides realtime directional and natural gamma ray measurements, transmitting them to the surface using mud pulse telemetry; but it has no additional formation sensing capability. The project work plan was to bring this system to full LWD capability by adding $\mathrm{HT}$ resistivity and porosity logging sensors and by upgrading the telemetry to accommodate the additional sensors. Because of concerns about the viability of density tool technology in the HT environment, the project initially called for including only a neutron porosity sensor. Later these concerns were alleviated, and a HT density measurement was added to the project.

In addition to the system test concluding Phase I, the HT tools have been run in a number of commercial wells with bottom hole temperatures in excess of $150^{\circ} \mathrm{C}$. A summary of the results from these wells is included in this report.

One of the goals of DOE's funding of developments of this type is to spur further developments. Near the end of the HT-LWD project, Sperry-Sun selffunded a HT version of its advanced controller, the "Central Interface Module" (CIM). A HT version of this module (HT-CIM) makes the system more versatile, allowing inclusion of other HT logging tools in the system as they become available. In addition Sperry-Sun has upgraded two other sensors to HT-LWD 
capability: the Bimodal Acoustic $\left(\mathrm{BAT}^{* *}\right)$ tool and the Pressure While Drilling (PWD) tool.

\section{Project Background}

Oil well logging is the process of acquiring data for formation evaluation (FE), the purpose of which is to determine the location of hydrocarbons in the formation, as well as to estimate the quantity in place. The primary measurements on which FE relies are the natural gamma ray, resistivity, neutron porosity, and bulk density. The gamma ray and resistivity measurements locate formations which are likely to contain hydrocarbons. The neutron and density measurements are used to discriminate between oil and gas ${ }_{2}$ as well as to determine the volume of hydrocarbons in the formation. '(Fiqure 1. Log Example )'

For most of the history of well logging, well logs were obtained after the well was drilled. Tools were lowered into the well, and the measurements were obtained as the tools were pulled from the hole by a wireline, which provided both the power and the telemetry for the tools. During the 80 s and 90 s, tools for making these measurements were designed into drill collars for logging while drilling (LWD). Sperry-Sun Drilling Services was a pioneering company in this field, introducing the first LWD neutron and density measurement tools, as well as the first electromagnetic wave resistivity $\left(E W R^{\star *}\right)$ tool. The electromagnetic wave technology evolved to become the most popular type of LWD resistivity measurement in the industry.

While one goal of LWD is to replace wireline measurements, it also has become an essential technology in other areas, providing measurements which enable precision horizontal drilling and real-time information that can significantly enhance drilling efficiency and well safety.

LWD FE sensors, along with telemetry modules for communicating data to the surface in real time, are built into drill collars of various sizes to allow LWD throughout a well. (Typically wells are begun with a larger diameter drilling bit, and smaller bits are used as the well depth increases.) Until recently, most LWD tools had a maximum operating temperature of around $150^{\circ} \mathrm{C}$. This provided LWD capability in most of the reservoirs of interest in the world. However, deeper wells where gas is frequently found can exceed this temperature.

To increase its presence in the HT market, in the 1990s Sperry-Sun developed the Solar 175 tool. This is a HT version of a Sperry-Sun system for economically making real-time directional and gamma ray measurements. Since borehole diameters in the deeper, higher temperature wells tend to be smaller, the Solar 175 tool was constructed in the smaller $4 \% 3$ " diameter drill collar. This system provided the starting point for the HT-LWD system of this project.

${ }^{\star \star}$ BAT and EWR are trademarks of Halliburton Energy Services, Inc. 
Project DE-AC26-97FT34175, "High Temperature LWD Project" was partially funded by the U.S. Department of Energy in September 1997 with Sperry Sun. After this project began, Dresser Industries, the parent company of Sperry-Sun, merged with Halliburton Company. Previous to the merger, Halliburton also had a sub-contract under Maurer Engineering. Maurer was contracted with DOE to build a HT, real-time directional/gamma system, consisting of modules for communication, power, directional, and natural gamma ray measurements. The technology and development departments of Halliburton and Sperry Sun were integrated, and the Maurer/Halliburton DOE contract was completed, resulting in a system qualified to operate at $195^{\circ} \mathrm{C} .{ }^{\dagger \dagger}$ The knowledge gained in the Halliburton DOE contract contributed to the HT-LWD project.

\section{System Description}

LWD systems are designed to acquire and record basic logging data while drilling and to transmit logging data to the surface using mud pulse telemetry. Well bore directional data transmitted to the surface are used to control the path of the well bore to the target formation(s). Data from other LWD sensors are used to evaluate these targets, to help make real-time drilling decisions, to detect well problems, and to provide "fine-tuning" to the well path (known in the industry as "geo-steering").

The HT-LWD system of this project combines modules from different Sperry-Sun systems. From the Solar 175 tool came the Telemetry Module (TM), Pulser/Generator, and the directional module (DM). From Sperry-Sun's other LWD systems come the gamma ray (DGR) tool, electromagnetic wave resistivity (EWR-P4) tool, compensated thermal neutron (CTN) tool, and stabilized lithodensity (SLD) tool.

As noted above, HT sections of wells tend to be smaller diameter and therefore the system specification called for capability in collars as small as $4 \frac{3 / 4}{4}$, for hole sizes in the 6" nominal range.

The tool modules are housed in drill collars, which are thick walled drill pipe located immediately above the drilling bit. The Solar 175 modules are in sondes which are installed in the central bore of the drill collars, while the remaining FE sensors are installed in annular inserts in the drill collars. In the case of the resistivity and density tools, the inserts are connected electronically to sensors which are located in the periphery of the drill collar. Brief descriptions of all these modules follow.

\footnotetext{
${ }^{{ }^{\dagger \dagger}}$ The final report for the project is 'Development of a Mud-Pulse High-Temperature Measurement-While-Drilling (MWD) System", January 2002, DE -AC26-97FT34345, Maurer Technology Inc. and Sperry-Sun.
} 
Pulser/Generator. Power for the system is generated in this 'modulei with a turbine driven by mud flow through the tool. The turbine also runs a hydraulic pump which operates a poppet valve that restricts the mud flow, creating pressure pulses in the inner bore of the drill string. These pulses are the means of transmitting the data to the surface. Bit rates are a few bits per second, approaching $10 \mathrm{bps}$ in mild environmental conditions.

Telemetry Module (TM). The telemetry module communicates with the other tools as well as with the pulser generator. The TM creates a transmission sequence of the sensor data for the pulser ${ }^{\ddagger \ddagger}$, controls the pulser operation, and conditions the power from the pulser/generator for use by the other modules. Data transmission with the pulser is possible only when the pumps are on and mud is flowing in the bore of the drill string. Other than sensing when pumps are on or off through the motion of the impeller in the pulser, communication between the TM and the surface is one way. $^{\S \S}$

Directional Module (DM). This modulei contains three-dimensional magnetometer and accelerometer sensors. The data acquired are used to calculate the direction of the well bore at each survey point (typically every thirty feet during drilling pauses for insertion of an additional "joint" of pipe in the drill string). On the surface, this information can be used to guide the well to a predetermined target chosen by some other means, usually a seismic survey.

Battery Module (BM). Mud flow and the power generated from it are not continuous during the drilling operation, so a battery module, is necessary to maintain operation of the electronics during drilling pauses. It is during the drilling pauses, for example, that the most accurate directional information is acquired. BM battery cells are available in several temperature capability ranges, up to $180 \mathrm{C}$.

Electromagnetic Wave Resistivity Phase 4 / Dual Gamma Ray (EWRP4-DGR). The natural gamma ray and resistivity modules are located together in one drill collar. The most basic function of the gamma ray measurement is to discriminate between porous rocks which may contain hydrocarbons (sandstones, limestones) and rocks which do not (shales). The measurement is a count of gamma rays from the inherent radioactivity of the formation and exploits the fact that shales are usually more radioactive than sandstones or limestones. In this project, the gamma rays are detected by

\footnotetext{
¥¥ The TM transmission scheme initially used Manchester encoding, where data are phase encoded into a regular clock cycle. A "1" or a " 0 " is encoded in the middle of each clock cycle, where a " 1 " corresponds to a rise in pressure, and a " 0 " to a fall in pressure. One improvement of this project was to change the encoding scheme to the more efficient pulse position modulation method (see below).

$\S \S$ Greater bandwidth "downlink" technology is available in the form of Sperry's GeoSpan ${ }^{\mathrm{TM}}$ technology, which can transmit complex commands from the surface to downhole. Instead of the TM, this system requires the CIM and PWD modules (see below) downhole.
} 
Geiger-Mueller (GM) tubes. The tool is referred to as a "dual" measurement because the tubes are arranged in two independent but otherwise redundant banks. An individual tube is a gas-filled cylinder with a wire running along its central axis. Gamma rays passing through the tube create a detection event when they produce electron-ion pairs in the gas or inner wall of the cylinder. The tubes operate with an electric potential between the wire anode and the tube wall that is sufficient to initiate an avalanche of charge to the anode. The resulting electrical pulse on the anode is registered in the counting electronics. Other technologies, such as sodium iodide scintillation detectors, are more efficient gamma ray detectors; however, GM tubes perform adequately at temperatures well above those at which scintillation systems seriously degrade or cease to function.

The resistivity measurement (EWRP4) is used to discriminate conductive porous formations containing brine from those resistive formations containing hydrocarbons; it is also used to infer the relative fractions of hydrocarbons and brines in a formation when both are present. Resistivity is determined from the difference in phase at two receiving antennas of an electromagnetic wave transmitted through the formation. Four different phase measurements are acquired, using four transmitters located at different spacings from the receiver pair. The sensitivity to the formation away from the borehole increases with increasing transmitting antenna spacing. The resistivity of the fluid in the borehole is usually different from that of the formation, with a transition - or invasion - zone between them. The four different measured values of resistivity can be combined in computer models to compute values for the resistivity of the borehole, the invaded zone, and the formation.

Compensated Thermal Neutron (CTN). The neutron measurementis a means of determining the porosity of the formation containing brine or hydrocarbons. The total volume of hydrocarbons in place may be estimated once the porosity is known.

The neutron measurement exploits the fact that high energy neutrons emitted into the formation are slowed through collisions with atoms in the formation. Because the hydrogen nucleus has nearly the same mass as the neutron, it is the most efficient element in slowing neutrons to thermal energies. In porous rocks, hydrogen is usually present only in the water or the hydrocarbons occupying the rock pore space. Thus, a measurement of the thermal neutron concentration around the neutron tool can be used to compute the amount of hydrogen in the formation and, in turn, the porosity of the formation.

The tool employs a source of high energy $(\sim \mathrm{MeV})$ neutrons and two detectors which are sensitive to neutrons at thermal energies $(<1 \mathrm{eV})$. The neutron detectors are proportional counters filled with helium-3 gas. In a detection event, a thermal neutron combines with a helium-3 nucleus in an 
exothermic reaction releasing a precise and repeatable amount of energy that ionizes the gas in the tube. The subsequent proportional action of the tube results in an electrical pulse of repeatable amplitude. This reproducibility allows neutron events to be distinguished from other, usually lower amplitude, events caused by other ionizing radiation such as gamma rays.

Porosity is computed from the ratio of the response of the two differently spaced detectors. Certain environmental effects, such as borehole and formation salinity, can be proportional in both detectors. Their effect is therefore reduced in the ratio of the detector responses. The conversion to porosity is accomplished by applying a succession of corrections which deal with the effects of hole diameter, formation fluid density and salinity, formation salinity, tool position within the borehole, and formation type - factors the values of which may either be assumed or determined from other measurements.

Stabilized LithoDensity (SLD). The SSLD tooli'is Sperry-Sun's version of the gamma-gamma density measurement tool which is used throughout the wireline and LWD industries. Gamma rays emitted by a radioactive source, usually cesium-137, scatter from electrons into the borehole and formation, losing energy as they scatter. They are registered by two detectors differently spaced from the gamma source. The primary mechanism for interaction of higher energy gamma rays with the formation is scattering from electrons, the concentration of which is proportional to the formation bulk density. The number of lower energy gamma rays is also affected by photoelectric absorption, which is a function of the chemical constitution of the formation. The density of the formation is inferred from the number of higher energy backscattered gamma rays detected. By comparing the number of high and low energy gamma rays, information about the mineralogy may be obtained as well.

The detectors consist of sodium iodide scintillators paired with photomultiplier tubes (PMT). Gamma rays interact with electrons in the sodium iodide crystal to produce scintillations, which are in turn converted to electrical pulses by the PMT. The pulse amplitudes, which are proportional to the gamma ray energy producing the scintillations, are digitized and stored by the electronics. This provides an energy discrimination capability which enables the tool to provide a measure of both the formation density, as well as an indication of the formation mineralogy (e.g., limestone, sandstone, or dolomite).

Of the FE tools discussed above, the density tool senses the smallest volume of formation in the process of making its measurement. This property is exploited in some tools by acquiring data "azimuthally" - that is, combining density measurements with simultaneous determination of the orientation of the tool in the borehole. Since the tool is usually rotating within the hole, this allows a $360^{\circ}$ density "image" of the formation near the borehole to be constructed. Such images are useful in well bores where the formation density is non-uniform around the well bore, either because of formation heterogeneity, or because the 
well bore is crossing a boundary between different formation layers. The latter case is important in geosteering applications where precise placement of the well bore within the formation is required. This imaging capability is part of the most advanced Sperry-Sun density tools, and one of the final tasks in this project was to add it to the HT-SLD tool.

Central Interface Module (CIM). The CIM, also an insert-based module, performs all functions of the TM, but provides other capabilities as well. It has memory sufficient to store all tool logging data (the TM stores only transmitted data). It has a high speed download capability, and manages all sensors in the Sperry-Sun fleet In contrast to the TM, the CIM software can easily accommodate additional new sensors as they are developed. A HT version of the CIM is therefore the obvious next step in expanding the HT-LWD capability. Although it was not included in the DOE project for HT-LWD, Sperry-Sun has initiated a self-funded program to develop the HT-CIM.

Other Sensors. There are other sensors in the Sperry-Sun fleet, not specified as part of this project, which provide measurements that can be important to drilling safety and to the evaluation of deeper, HT wells. The Pressure While Drilling (PWD) tool measures the fluid pressure in the bore of the drill string and in the annulus between the drill string and the borehole wall. Realtime measurement of pressure can be of particular importance in the more difficult drilling situations and is useful in optimizing drilling practice and rig safety.

Sperry-Sun's Bimodal Acoustic (BAT) tool measures direct and shear acoustic velocities of the formation. These parameters are useful in FE as well as in drilling optimization. The principal elements of the tool are a pair of diametrically opposed acoustic transmitters mounted in the drill collar, and an array of seven transducer-receiver pairs, also diametrically mounted. The coherency of the waveforms arriving at the seven receivers allows extraction of the various acoustic velocities of the formation (e.g., compressional and shear). The PWD and BAT tools have been upgraded to $\mathrm{HT}$ (i.e., $175^{\circ} \mathrm{C}$ ) or near $\mathrm{HT}$ status and can be deployed in a HT system when the HT-CIM is used. 


\section{Project Tasks and Accomplishments}

The major tasks and accomplishments of this project will be discussed in this section. The testing and integration procedures that Sperry-Sun uses to insure reliable operation of its tools for extended periods in hostile operating conditions will be outlined as well. Halliburton and Sperry-Sun have a number of environmental and mechanical testing facilities for qualifying and troubleshooting LWD tools. These are outlined briefly in the following table:

\begin{tabular}{|c|c|}
\hline \multicolumn{2}{|r|}{ Halliburton Testing Facilities } \\
\hline Vibration & $\begin{array}{l}\text { Multiple tables, exceeding } 25 \mathrm{~g} \text { RMS, 3-axis mounting, } \\
\text { simultaneous } 200^{\circ} \mathrm{C} \text {. } \\
\text { Random shocks of several Kg's }\end{array}$ \\
\hline Pressure & $\begin{array}{l}\text { Six pressure vessels, } 35 \mathrm{Kpsi}, 250^{\circ} \mathrm{C} \text { (Max volume }=12^{\prime \prime} \\
\left.(\text { Diam }) \times 27^{\prime}\right)\end{array}$ \\
\hline Flow Loops & $\begin{array}{l}\text { Several loops up to } 6000 \mathrm{ft} \text { in length. Two triplex pumps, up } \\
\text { to } 1400 \mathrm{gal} / \mathrm{min} \text {. }\end{array}$ \\
\hline Temperature & $\begin{array}{l}\text { Numerous ovens for testing/cycling components, boards, } \\
\text { inserts, and assembled tools. }\end{array}$ \\
\hline Fatigue & Full scale rotary/bending machine for drill collar testing \\
\hline $\begin{array}{l}\text { Mechanical } \\
\text { Testing Laboratory }\end{array}$ & $\begin{array}{l}\text { Variety of metallurgical testing capabilities -- hardness, } \\
\text { stress/strain, corrosion, \& chemical testing. } \\
\text { Microscopic, X-ray, SEM analysis. }\end{array}$ \\
\hline Sensor calibration & $\begin{array}{l}\text { Facilities for testing, calibration, and characterization of } \\
\text { nuclear and electromagnetic tools. } \\
\text { Resistivity tools - water tanks and air hang facilities for tool } \\
\text { characterization and calibration. } \\
\text { Nuclear tools - Tool Response and Characterization } \\
\text { Laboratory (TRAC Lab), with }>3 \text { dozen formations } \\
\text { and }>50 \text { borehole sizes for response measurement of } \\
\text { neutron, density and natural gamma ray tools. } \\
\text { Test wells and formations for testing tool \& system } \\
\text { operations under simulated drilling conditions. } \\
\text { Oven facilities for testing operating nuclear tool at } \\
\text { temperature. }\end{array}$ \\
\hline Drilling simulator & $\begin{array}{l}\text { Facility for testing downhole tools by drilling up to a } 60 \text { ' hole } \\
\text { in a concrete formation; includes triplex pumps and } \\
\text { top drive with up to } 120 \text { Klb weight on bit. }\end{array}$ \\
\hline
\end{tabular}


Testing Procedures and Processes. Sperry-Sun's electronic board development process includes qualification and integration testing at appropriate stages of assembly. Individual boards are functionally tested both on the bench and with "shake and bake" procedures - that is, operating while under vibration and HT simultaneously. The final qualification test for a board consists of successful, continuous operation at $175^{\circ} \mathrm{C}$ for more than 1000 hours. Integration testing continues on board sets as well as on complete assemblies, including assembled tool strings.

As indicated earlier, PC boards containing the electronics for the FE sensors are mounted on annular inserts which fit into bored out drill collars. The boards and inserts are installed in the drill collars at atmospheric pressure, and radial o-ring seals are used to secure the insert environment against downhole pressures.

For this project, the 0 -ring material was changed to a substance more stable against higher temperatures, and the o-ring design was modified as well. To verify the integrity of the redesigned seals, a series of pressure and temperature tests were performed. These tests began with a set of pressure cycles between atmospheric and high pressure ( $20 \mathrm{Kpsi}$ in this case) at normal temperature. They continued with a "soak" at maximum pressure and temperature $\left(200^{\circ} \mathrm{C}\right)$, followed by a repetition of the pressure cycles while the maximum temperature was maintained, and were concluded by repeating the pressure cycles at normal temperature.

PC Board Construction and Testing. A number of solutions for HT electronics already available from the Solar 175 tool project and the Maurer/Halliburton DOE contract were incorporated in this development. For example, the solder used in the standard tools becomes unstable above 165$170^{\circ} \mathrm{C}$, and shock and vibration failures increase rapidly. In HT tools, the solution to this problem is high melting point (HMP) solder. Of course, the assembly of boards with HMP solder is more difficult and expensive. The Solar 175 tool experience also provided more robust PC board materials, improved layout and staking methods, and some improved electronic modules (e.g., HT power supply circuits). These design considerations were applied in the redesign and re-layout of all the boards for the HT sensors.

Solar 175 Tool. Since the Solar 175 tool was already designed for high temperatures, the principal tasks for this tool were to upgrade the pulser and telemetry to accommodate the new sensors and higher data rates. The pulser stroke length was decreased, enabling an inc rease in data rate from $0.8 \mathrm{~Hz}$ to $3.0 \mathrm{~Hz}$. An upgrade kit for additional pulser modifications was developed to enable the pulser to handle its increased loads and flow velocities as well as to extend its lifetime downhole. 
Gamma / Resistivity. The resistivity tool incorporated into the HT-LWD system was Sperry-Sun's 4 3/4" electromagnetic wave resistivity (EWR) tool, the Slim Phase 4 (SP4) tool. The standard SP4 tool includes resistivity, gamma ray, and vibration measurements in a single drill collar. A principal task for modifying the resistivity sensor was to incorporate the Solar $175 \mathrm{GR}$ module into the resistivity collar. The GM-tube detectors and electronics of the GR module (a sonde in the Solar 175 tool) were redesigned and rebuilt to fit on the insert for the SP4 tool.

Other tasks were associated with the resistivity components of the SP4 tool.

- The SP4 tool originally was developed to run, if necessary, as a stand-alone, "smart" sensor. For the HT-LWD system, it was necessary to make the tool a slave to the TM, so it did not interfere with the TM Bus Master logic.

- The circuitry for communications between the SP4 tool and the TM was not reliable because some units of a particular component would fail above $162^{\circ} \mathrm{C}$. The solution to this problem was two-fold. The components were pre-tested to select those that would function to $175^{\circ} \mathrm{C}$, and these were used to build the first HT SP4 tools for field tests. Concurrently, a substitute module was developed using a temperature-qualified microcontroller programmed to do the communications. This module was installed in tools built later.

- Above $165^{\circ} \mathrm{C}$, the reset switch on the resistivity receiver board increasingly bled current; the switch was replaced with a circuit using a field effect transistor.

- Although other SP4 boards were tested and upgraded as needed to the higher temperature, the power board was targeted for redesign at the beginning of the project. The redesigned board functioned successfully.

CTN. Neutron detector mounting and more robust electronic designs were the primary issues to be solved for the neutron sensor. While the neutron pulses from the tubes are repeatable and typically greater in amplitude than competing events from other forms of radiation, the $y$ are nevertheless small enough that substantial preamplifier gains are necessary. To obtain the proportional operation, the central wire of the tube is quite small. The small wire diameter and pre-amp gain combine to make the tubes and electronics susceptible to vibration induced electrical pulses.

Most $\mathrm{HT}$ upgrades involved extending lower temperature solutions for these issues to the higher temperature regime:

- Tests showed that shock-absorbing foam materials used in detector mounting became brittle and vibration-inducing at higher 
temperatures. These were replaced by a material which retained desirable properties at higher temperatures.

- Critical plastic components on the pre-amp and high voltage boards were replaced with ceramic units which have robust, enduring performance at high temperatures.

- The high voltage (HV) required for the He3 tube operation (e.g. $>500$ volts) is a function of the gas pressure in the tube. Tube pressures were modified in order that effective operation could proceed.

SLD. Spectral sensitivity is the SLD tool feature that is most severely affected in higher temperature operations. PMT gain decreases with increasing temperature throughout the operational range of the tool, and PMT lifetime is noticeably foreshortened as the upper limit of the HT range is approached. To stabilize the tool response over temperature, a low activity "reference" source of gamma rays was installed adjacent to the sodium iodide crystal. This source produces a reference peak in the gamma ray spectrum, and gain stabilization is accomplished electronically by maintaining the position of this peak in the spectrum. by:

Electronic processing and digitization of the PMT pulses were improved

- replacing an $A D$ converter which shut down above $150^{\circ} \mathrm{C}$ with a unit that functions to $175^{\circ} \mathrm{C}$, and

- designing a more robust method for determining the peak location of the pulse at the time of digitization, resulting in increased linearity and uniformity of the energy spectrum with temperature.

The detector package modifications included:

- changes to reduce temperature effects on the relative positions of the components, further stabilizing the spectral response, and

- a redesigned HV supply to the PMTs, extending their effective lifetime at higher temperature operation.

Tests of the new system at $175^{\circ} \mathrm{C}$ indicate that the useful lifetime of PMTs in the HT SLD can easily exceed 500 hours, considerably above the initial target.

Other FE Sensor Modules -CIM, PWD, and BAT Tools. The TM provides support for the resistivity, neutron and density sensors. In order to add other sensors to the high temperature system developed within this project, Sperry-Sun upgraded to high temperature capability its more versatile and powerful controller, the Central Interface Module (CIM). The upgraded units routinely function up to $170^{\circ} \mathrm{C}$. However certain key electronic components unique to this module have not proven reliable to $175^{\circ} \mathrm{C}$. To achieve reliable 
operation at this temperature it is necessary to pre-select individual components through high temperature screening.

The CIM enables more powerful programming options for the LWD system. For example, the CIM software was modified to encode the data using "pulse position modulation" (PPM). Using PPM, the data are encoded in the time intervals between a stream of successive pressure pulses, with several bits included in each interval. This method increases the average number of bits per pressure pulse over the Manchester encoding scheme used in the PM, and thereby has beneficial effects on efficiency and pulser lifetime. Althoug h new to Sperry-Sun's positive pulse system, the method of PPM encoding has been successfully used for the life of Sperry-Sun's negative pulse system.

Although not part of the HT-LWD project, two other tools in Sperry-Sun's LWD fleet have been upgraded to HT operation - Sperry-Sun's Pressure While Drilling (PWD) tool and the Bimodal Acoustic (BAT) tool (see Other sensors in System Description page13). Finally, as indicated in earlier portions of this report (see SLD Tool in System Description page13), a HT azimuthal measurement capability was added to the HT density tool.

\section{Field Test Results}

The Phase I system test was conducted in South Texas in 2003. In this test the tools were operated downhole; the data were transmitted to the surface using the mud pulse telemetry system; and logs were generated from the transmitted data. At the request of the operator, logging took place not while drilling but on a "wipe"; that is, during a circulating trip into the hole following drilling. Nevertheless, all logging and real-time telemetry functions of the system were operational and performed appropriately.

In the 20 months since the Phase I test, Sperry-Sun has run its HT-LWD tools in at least $35 \mathrm{HT}$ wells, in both domestic and international markets. However, in the domestic HT market, the operators Sperry-Sun serves chose to employ a more limited service consisting of the EWR/DGR combination, accompanied often by a sonic (BAT) or pressure while drilling (PWD) tool. This is a common practice for "standard" temperature wells in the Gulf of Mexico. Thus, for the purpose of reporting on the full service HT-LWD operation in HT wells

${ }^{* \star *}$ Sperry operates two types of mud pulse communication systems. The positive pulse system works by briefly constricting the mud flow in the bore of the drill string. Prior to this project the positive pulse system employed Manchester encoding, as mentioned previously in this report.

The negative pulse system releases a short stream of mud from the bore to the annulus through a gate valve in the wall of the tool. This produces a momentary drop in the bore pressure by virtue of the pressure difference between the bore and the annulus (typically several hundred psi). Pulse position modulation (PPM) has been used in this communication system. With PPM the information is encoded in the time intervals between pulses. The band width of this method is determined by the attenuating properties of the mud; practically, several bits per second can be achieved, and ten bits per second are possible under ideal conditions. 
(Phase II of this project), wells in the domestic market were less than ideal. HT jobs employing the full HT-LWD system were drilled, but these were all in the international market. There were two jobs that Sperry-Sun regarded as particularly significant tests for the system, and these will be discussed briefly below.

The first full service test occurred in a series of HT wells drilled in the Thailand market. This series of wells was very significant in validating and completing the system development, and highlighting procedural and hardware weaknesses. The maximum downhole tool temperature recorded was $171^{\circ} \mathrm{C}$. The circulation of the drilling mud has a cooling effect on the tools; and, as a result, the tool temperature may be as much as $10^{\circ} \mathrm{C}$ or even $20^{\circ} \mathrm{C}$ less than the actual formation temperature. Nevertheless, the HT-LWD system should be rated to the formation temperature, as the higher formation temperature may be encountered during tripping into the hole or during unplanned drilling stoppages.

As a result of the experience with these wells, improvements were also made to the battery module. A HT azimuthal module was added to the density tool, giving it the ability to produce a low resolution image of the borehole wall. The limitations of the TM module, originally designed for a simpler directionat only system, were highlighted by the difficulty of handling the full-service tool string which included the redesigned density tool. This spurred efforts to bring the HT CIM module on line for inclusion in the HT-LWD system as soon as possible.

The first important test of the full HT-LWD system that included the HTCIM occurred in a Norway HT well. Although the LWD measured temperature for this well was barely $150^{\circ} \mathrm{C}$, the HT capability was required for the job because of the expected higher formation temperature. The real-time logging of this well was made possible by the development of the HT sensors and by the HT density tool in particular. The well was drilled in three sections, beginning with a $121 / 4$ " diameter hole, and completed with a smaller diameter 6" section where the HT sensors were required. The test was very successful, with all sections including the bottom one completed with no separate bit trips required because of LWD failures. The final HT section of the well was drilled with a diameter of 6 ", to a final measured depth of $5354 \mathrm{~m}(17566 \mathrm{ft})$, or about $3800 \mathrm{~m}(12,467 \mathrm{ft})$ true vertical depth. The HT sensors operated for a total of 420 hours, with 154 of those being circulating real-time telemetry hours.

In addition to the two HT-LWD logging jobs discussed above, a brief survey was undertaken of reports from other HT wells (defined as those whose maximum bottom hole temperature exceeded $150^{\circ} \mathrm{C}$ ) logged in the period since the Phase I field test. As indicated above, these included both jobs with a full service LWD system in the hole as well as jobs with a partial system but which might include PWD or BAT sonic sensors. A measure of the reliability of the system is the frequency of service interrupts - that is, the number of system failures which adversely affect routine delivery of the LWD service. Service interrupts occur red on some of the HT wells; however, none turned out to be due 
to failure of the mechanical or electrical HT designs or to unus ual environmental conditions which were specific or unique to the HT situation.

\begin{tabular}{|ccccccc|}
\hline \multicolumn{7}{c}{ High Temperature LWD Field Tests } \\
Region & Date & $\begin{array}{c}\text { Max } \\
\text { Downhole } \\
\text { Temp }\end{array}$ & $\begin{array}{c}\text { Hrs } \\
\text { Operating }\end{array}$ & $\begin{array}{c}\text { Hrs Cir- } \\
\text { culating }\end{array}$ & $\begin{array}{c}\text { Hrs } \\
\text { Drilling }\end{array}$ & Comments \\
USA & May-03 & $<150^{\circ} \mathrm{C}$ & N/A & N/A & N/A & Phase 1 integration test \\
Thailand & Oct-03 & 171 & 233 & 120 & 90 & $\begin{array}{l}\text { Commercial, 2 wells, 3 bit } \\
\text { runs }\end{array}$ \\
Norway & Feb-04 & 149 & 420 & 220 & 94 & $\begin{array}{l}\text { Commercial, 1 well, HT- } \\
\text { CIM, HT-PWD }\end{array}$ \\
\hline
\end{tabular}

\section{Economic and Market Considerations - the Need for HT LWD}

LWD is being drawn into the HT market as a solution to many of the challenges of drilling HT wells, and as an essential element of certain advanced well construction strategies necessary to exploit the economic potential of HT reservoirs. Further development of HT technology will be driven by market "pull", but also should be "pushed" in recognition of the long term national interest as the country's energy requirements further exceed domestic supply.

The HT market is currently a small fraction of the overall drilling market, but one whose significance will grow as energy demand increases and current reserves are depleted. In the United States the principal HT prospects are the western Gulf of Mexico, South Texas, Louisiana, and Mobile Bay. In the proposal for this work, Sperry-Sun estimated the total US market for new wells above $150^{\circ} \mathrm{C}$ to be approximately 900 per year, with approximately 60 of those being offshore in the Gulf of Mexico. Although an update to those estimates was not undertaken as part of this report, there almost certainly has been less activity on land than was anticipated earlier. However, the volume of Sperry-Sun's HT work in the Gulf of Mexico appears to have remained consistent with that estimation.

A survey of Sperry-Sun's activity during the last decade suggests the growing significance of high temperature work in the market. The following graphic shows the fraction of Sperry-Sun's work that took place in wells with a measured temperature exceeding $140^{\circ} \mathrm{C}^{*}$, along with corresponding annual average prices for oil and gas. The fraction of Sperry-Sun's market that falls within this "high temperature" range shows a robust growth rate of $\sim 1 \%$ per year

\footnotetext{
${ }^{*}$ It is assumed that the formation temperature is, on the average, $10^{\circ} \mathrm{C}$ higher than the temperature measured by the tool. A measured downhole temperature of $140^{\circ} \mathrm{C}$ corresponds, then, to a formation temperature of $150^{\circ} \mathrm{C}$.
} 
in the periods from 1995 to 1999 , and 2001 to the present. Higher cost activities such as HT drilling are especially sensitive to adverse economic conditions. The dip in activity correlating with the recession early in the decade illustrates this. Generally, the data suggest an industry growth for drilling in higher temperature situations.

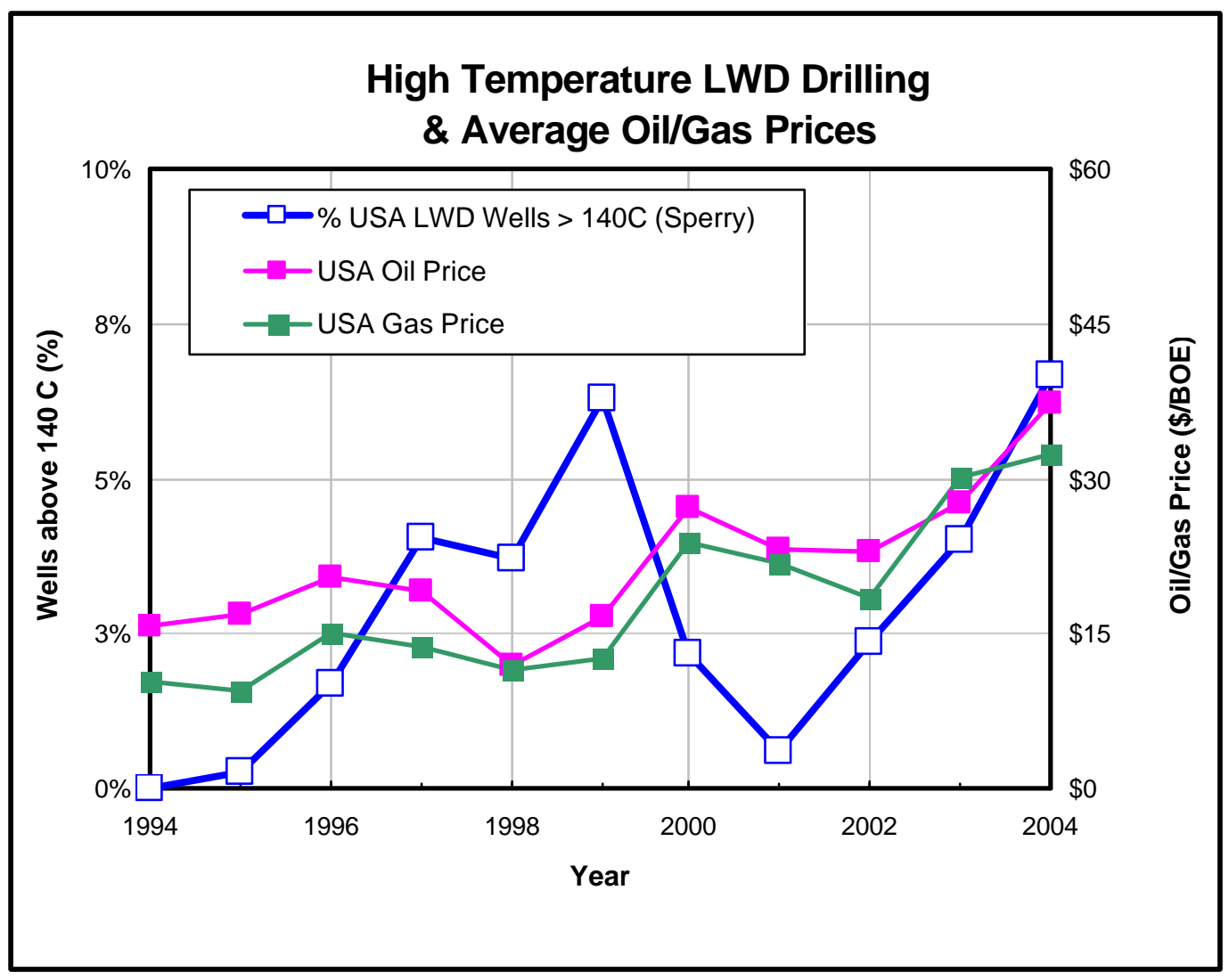

Although future fluctuations in the market should not be ruled out, drivers supporting long-term price increases seem to be in place. For example, consumption in the United States has continued to increase and the growing economy of China has begun to use oil in significant amounts. Refining capacity is also a factor in prices, but the increasing perception that demand is approaching and may soon exceed the world's maximum production capacity will surely have a significant and permanent effect on hydrocarbon price structures.

In considering how LWD will benefit high temperature drilling, it is useful to review a number of drivers that have affected its success in the industry so far. Four drivers considered here include increased productive capacity, reduced rig time, reduced risk, and increased safety.

Increased production: Logging while drilling can enhance production and well bore value through maximi zing borehole exposure to hydrocarbons. For much of the life of the oil industry, wells were drilled to hydrocarbon bearing 
reservoirs from rigs situated vertically above the target. Today's drilling techniques allow deviated wells to penetrate a formation horizontally, exposing a much greater volume of the formation to production than would have been the case with a vertical well. Furthermore, a borehole may be directed to successively penetrate a number of target formations, the positions of which may differ widely in both horizontal and vertical extent. In addition, extended reach drilling and multilateral architectures are increasingly being employed to access more reservoir from a single platform. These new drilling practices, which involve precise placement of the well bore on the seismic model, require extensive use of LWD sensors. Since LWD sensors enhance the productive potential of a borehole and reservoir, they can be expected to be significant in determining the economics of high temperature wells.

Time/expense of drilling: For premium rigs where costs are as high as $\$ 200 \mathrm{~K} /$ day, the time required for wireline logging can be a significant component of the cost of drilling a well. In deeper wells, several days may be required to accomplish the tasks of tripping the drill pipe out of the hole, conditioning the hole for the wireline log, and running the log. For more complicated wells where high pressure is an issue, additional wireline logs may be required at intermediate points in the drilling program. Elimination of wireline logging is therefore a major benefit of running LWD. Furthermore, LWD provides real-time logging data which can immediately benefit drilling decisions, rather than only on an occasional basis following a wireline logging run. This increases the probability of success in drilling difficult wells.

Risk reduction: In deeper, hotter wells, the formation properties and the borehole itself are increasingly active and unstable. When the open hole is exposed to the drilling fluids, particularly during the period between the end of drilling and the completion of the well, significant formation damage or even loss of the well may occur. Invasion of the formation by borehole fluids to the point of completely masking the presence of hydrocarbons is possible, and the risk of this occurrence increases in high temperature gas wells. Reducing the exposure time by eliminating wireline logging reduces this possibility, and real time LWD logging, which usually follows drilling by only a few minutes, virtually eliminates the possibility that the presence of hydrocarbons will be missed because of invasion.

Safety: Unanticipated penetration of over-pressured zones and subsequent loss of control of the well is probably the most significant safety hazard. Always a concern in oil and gas well drilling, this is a hazard which will increase in frequency in high temperature wells. Although the presence of overpressured zones can be predicted from seismic data, their precise location from seismic data alone is always uncertain. One of the most effective ways the approach of such zones can be detected is through well log analysis. Its provision of real-time logging data makes LWD an effective tool for dealing with these hazards. 
While demand may drive new technology development, new technology in its turn may drive the market. As an example one may observe that initially most LWD tools were designed and manufactured in the $63 / 4$ " drill collar diameter, which was consistent with the fact that the corresponding $81 / 2$ " bit size was the one most often chosen to penetrate target zones. Subsequently development of re-entry and multilateral technology, which meant drilling out from existing holes with even smaller bit sizes, drove development of the first $43 / 4$ " LWD tools. These tools, in turn, then allowed directional wells with smaller hole sizes to be planned since they could be directed and logged with the smaller LWD tools. Analogously, increasing availability and capability of HT LWD may encourage operators to plan and execute drilling programs in high temperature reservoirs previously not seen as economically viable.

It is expected that most HT wells will be drilled with bottom hole sections in as small as 6 " nominal diameter, consistent with the current $43 / 4$ " tool size developed. Certain future HT applications (e.g. HT reentries) may include 4 3/4" nominal hole size, necessitating even smaller (e.g. 3 3/8") tool diameters.

Development of HT-LWD tools will occasion higher tool costs, increased costs of depreciation, personnel, maintenance, and replacement parts. Today's more limited markets for HT measurements support only a smaller tool fleet, resulting in a more limited utilization of tools. This pushes the cost basis higher. These higher costs can be discouraging to further development, since higher costs must be justified by demand. While the HT market is sensitive, it has been Sperry-Sun's experience that there is a need for these tools and that the market may support the associated higher revenue requirements.

\section{Conclusions and Recommendations}

The goals of the project as stated in the initial project plan were achieved. As the project progressed through development and testing, it became clear that broader goals would be required to achieve an effective system. It was in achieving some of these expanded goals, and in investigating yet higher temperature systems, that the next challenges to high temperature became apparent.

1. The original goal of developing and field testing a HT-LWD system was met. Techniques and procedures have been developed for designing and upgrading sensors to HT capability. Key electronic issues were addressed using more robust circuit element designs and ceramic components in key areas. This included nuclear detection components and redesigned electronic circuits for nuclear tools. Improvements were also made in the telemetry system, accommodating the higher band width requirements of the additional sensors as well as making the system more durable and reliable in the harsh environment. 
2. The design of the system controller for the project (the TM) could not support additional modules, such as sonic and pressure while drilling sensors, which will meet anticipated demand for the richer data set. Inclusion of the CIM module in the HT development was a step in making a broader suite of measurements available to the HT market. The difficulty of obtaining particular high temperature components unique to this sensor illustrates the barriers that remain to constructing high temperature tools.

3. Although some electronic components are available for temperatures above $175^{\circ} \mathrm{C}, \mathrm{CPU}$ and memory devices required for complete sensors are not. More robust technologies are required to overcome this constraint.

4. Nuclear sensors are the backbone of porosity logging. However for operating temperatures above $175^{\circ} \mathrm{C}$, and particularly for extended downhole operation required by LWD, the operation and longevity of scintillation technologies is a serious problem. Geiger Mueller tubes and proportional counters may be used, but can be much less efficient than scintillation techniques. Other approaches to nuclear detection are desirable. Furthermore, high voltage operation is increasingly difficult at higher temperatures. More robust circuit and design components (e.g., capacitors, connectors) are needed.

5. Long term strategic investment is required to develop the technologies needed for higher temperature LWD capability. The electronics industry, deriving its profits from high volume production, is unlikely on its own to develop HT components which would serve the more limited HT oil and gas drilling market. Halliburton itself has invested several million dollars in development of high temperature logging capability. However, it has become clear that the service industry alone cannot bring these technologies to fruition. If frontier energy resources are to meet the country's energy needs, such an investment must be made. The current DOE sponsored SOI development effort, in which Halliburton participates, is an example of how this can be done. (Of course, this particular SOI development must be expanded before current HT-LWD systems can be fully upgraded moved to significantly higher temperature regimes.)

6. This and earlier projects have focused on incremental and systematic improvements on current technology and concepts for operation at successively higher temperatures. Certain technologies currently in research or early development may facilitate a fundamentally new approach, as a means of attaining the next temperature hurdles. For example, current low real-time data transmission bandwidth requires concentration of data processing and storage capability downhole. Reliable "hard wired" drill pipe technologies in development might remove this constraint and allow, in turn, extensive simplification of downhole electronics. 
Appendices 
THIS PAGE DELIBERATELY LEFT BLANK 
ACRONYMS IN THE REPORT BODY

\begin{tabular}{|c|l|}
\hline Acronym & \multicolumn{1}{|c|}{ Meaning } \\
\hline AmBe & Americium beryllium \\
\hline BAT & Bimodal acoustic tool \\
\hline BHT & Bottom hole temperature \\
\hline BM & Battery module \\
\hline CIM & Central Interface Module \\
\hline CTN & Compensated thermal neutron porosity tool \\
\hline DM & Directional module \\
\hline DOE & U.S. Department of Energy \\
\hline DGR & Dual gamma ray tool \\
\hline EWR & Electromagnetic wave resistivity tool \\
\hline EWRP4 & EWR Phase 4 resistivity tool \\
\hline FE & Formation evaluation \\
\hline GM & Geiger-Mueller gamma ray detector \\
\hline GOM & Gulf of Mexico \\
\hline HMP & High melting point (solder) \\
\hline HT & High Temperature \\
\hline HV & High voltage \\
\hline LWD & Logging while drilling \\
\hline MeV & Million electron volts \\
\hline MTBF & Mean time between failure \\
\hline MWD & Measurement while drilling \\
\hline PC or PCB & Printed circuit board \\
\hline PMT & Photomultiplier tube \\
\hline PPM & Pulse position modulation \\
\hline PWD & Pressure while drilling tool \\
\hline SEM & Scanning electron microscope \\
\hline SLD & Stabilized litho-density tool \\
\hline SOI & Silicon on insulator \\
\hline SP4 & Slim phase 4 \\
\hline TM & Telemetry module \\
\hline TRAC & Tool response and characterization \\
\hline & \\
\hline
\end{tabular}


Figure 1: Log Example

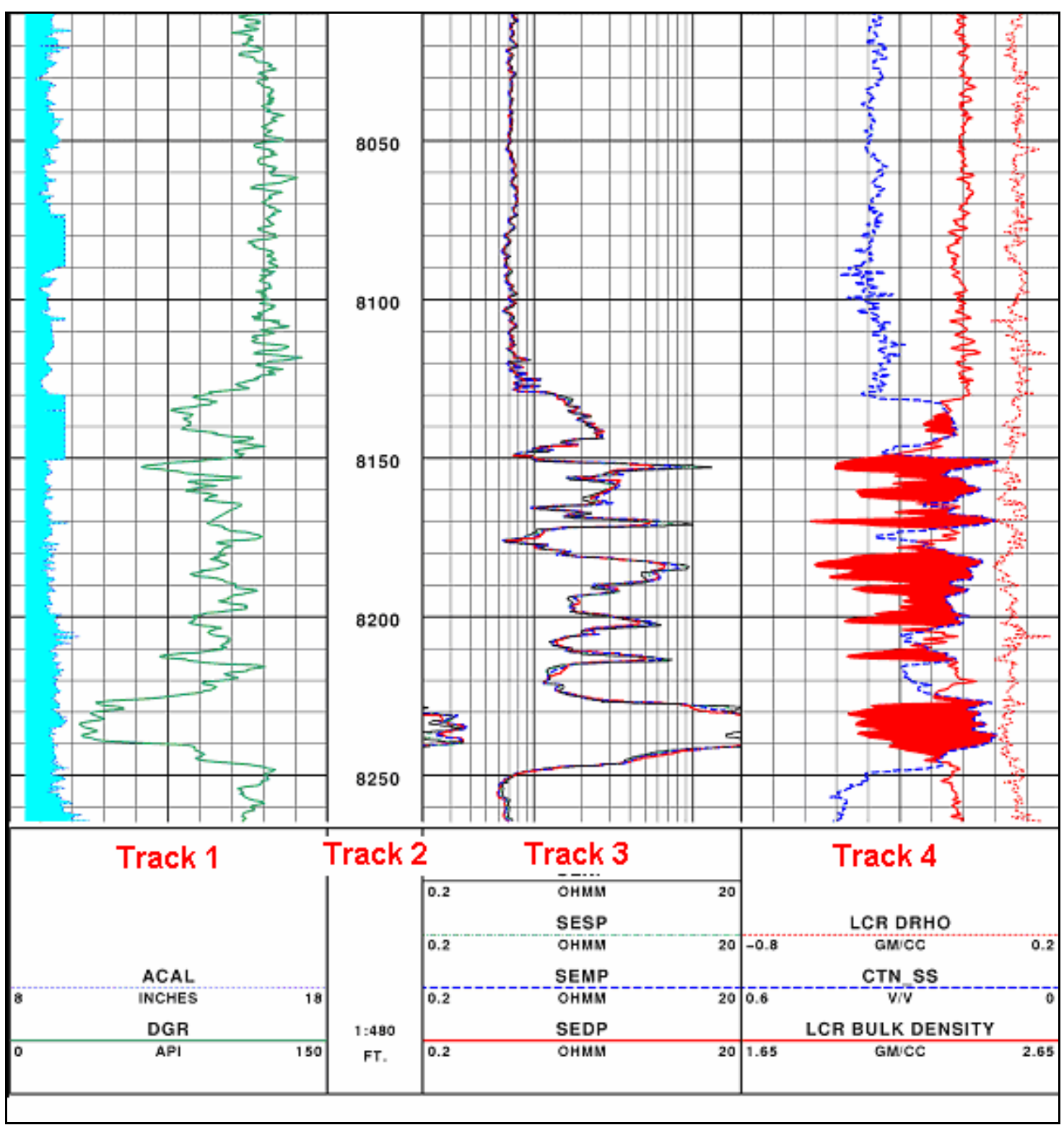

Well logs are divided into multiple tracks which plot various measurements as a function of depth. Track 1 (red label) contains a caliper, or hole diameter, log (blue curve) and a gamma ray log (in green). The depth values for the logs are indicated in Track 2 . The gamma ray shows that shales are at depths less than $8120 \mathrm{ft}$ (Track 2), with shale and sandstone mixed between 8120 and 8225 and a "clean" sandstone between 8225 and 8240 . The resistivity (Track 3 ) indicates the presence of hydrocarbons (high resistivity) in the sandy layers between 8120 and 8240 . Except for the zone 8225-8240, the resistivity "sees" more contrast than the natural gamma ray, probably because the resistivity is located in thin beds that the natural gamma ray is unable to resolve because of its low depth resolution. In Track 4 are the neutron (blue) and density (red) logs. Oil may be in the zone between 8130 and 8145 . Otherwise, these curves cross-over in the resistive zones, indicating the presence of gas. The cross-over is highlighted by shading in the area between the curves where they cross over. 
Figure 2: Pulser/Generator/Telemetry/GM/TM

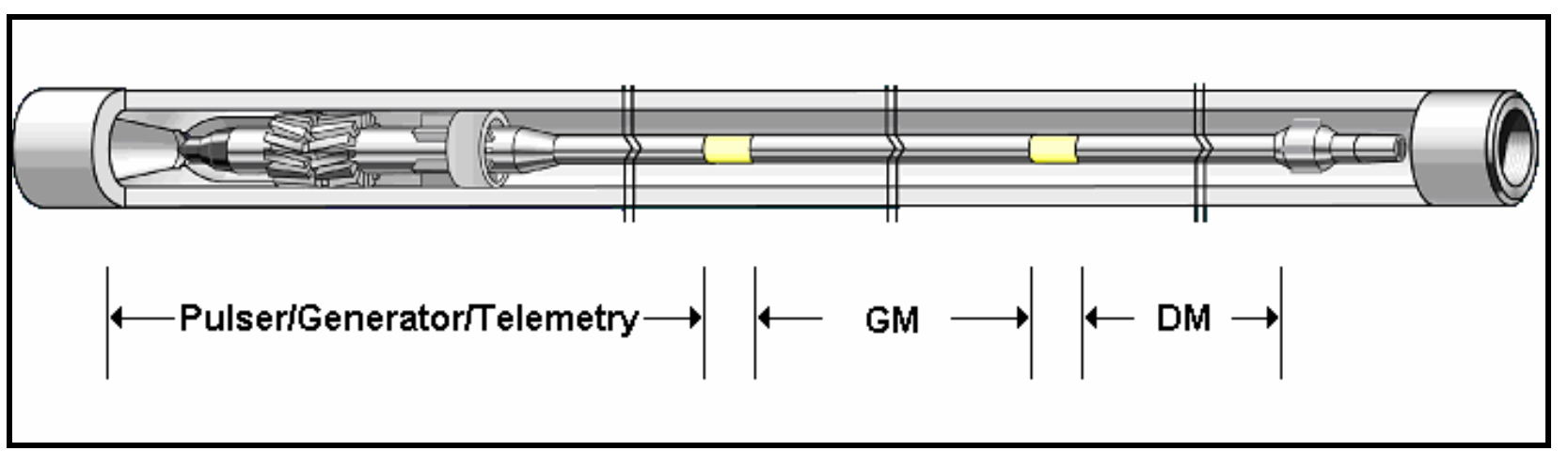

Pulser, Generator, Telemetry, Gamma (GM), and Directional (DM) modules in a drill collar. The modules are along the central axis of the drill collar. The pulser/generator section on the left in the drawing is installed at the top of the string. Drilling mud flows in the annular volume between the drill collar and the modules, from left to right in the drawing. The pulser is the left most element of the package (top of the downhole string) so that pressure pulses are not attenuated by other modules within the drill string bore. The GM module shown was removed from this section and installed in the gamma ray detection section of the EWR Slim Phase 4 tool (Figure 3).

\section{Figure 3: EWR Slim Phase 4 Tool}

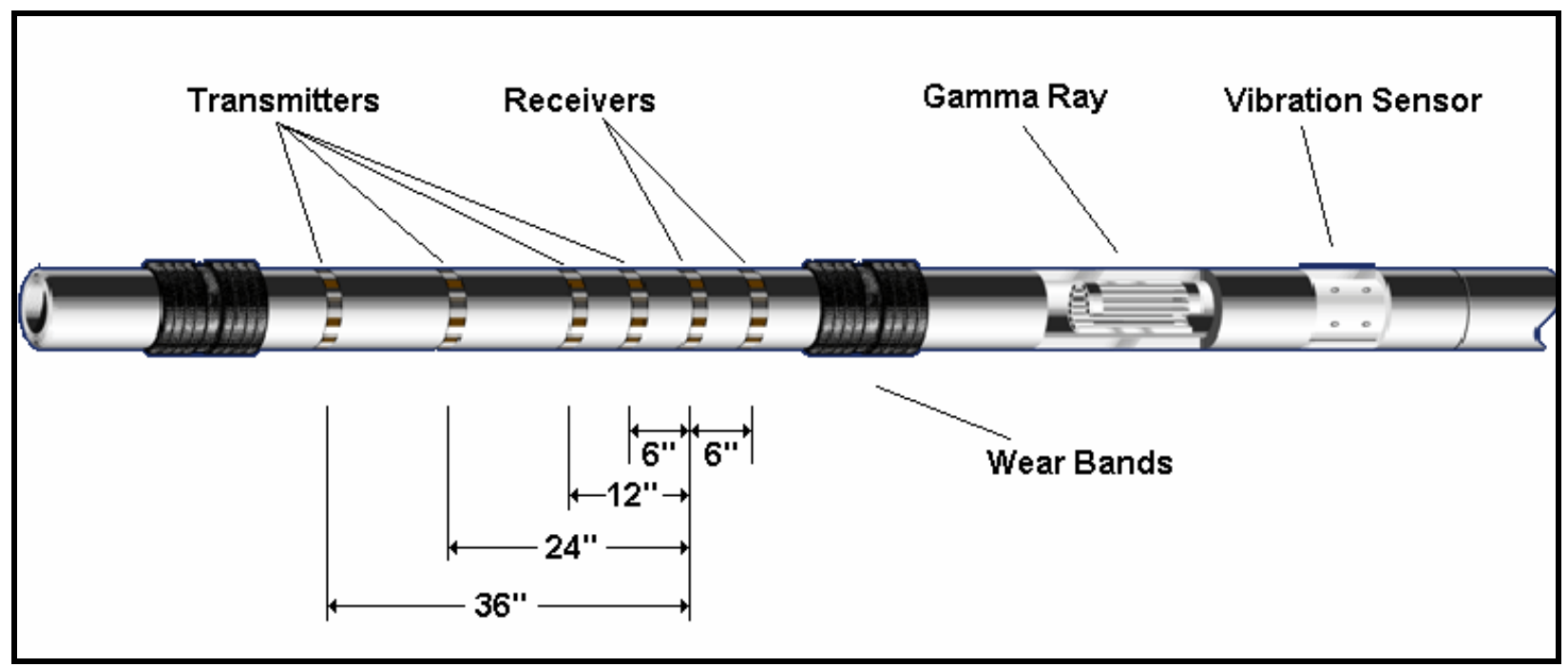

Resistivity/Gamma Tool. The EWR Slim Phase 4 is actually several tools in one drill collar. Four different resistivity readings, sensitive to various radial depths away from the borehole, are produced by waves emitted by the four differently spaced transmitters. The phase difference for each transmitter is measured at the receiver pair. The electronics inserts (not indicated in the figure) controlling the transmitters and receivers are located inside the bore of the drill collar immediately to the left and right, respectively, of the transmitter and receiver antennas. The antennas themselves are wire loops, installed in grooves around the tool and covered by the circumferential bands indicated in the drawing. The gamma ray detectors, indicated in the "cutout", are located on the receiver insert. A vibration sensor provides information about average $\mathrm{g}$ levels and maximum shocks experienced by the tool. The wear bands are carbide rings around the tool that abrade over time as a result of contact with the formation. They significantly extend the life of the tool and drill collar. 
Figure 4: CTN

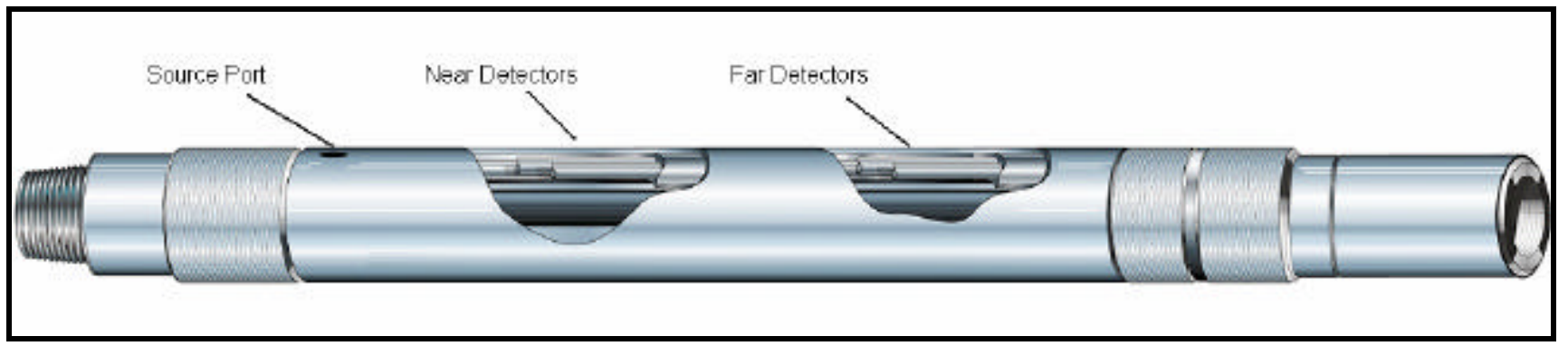

CTN Tool. The neutron source is installed in the source port just prior to the tool going downhole. Neutrons with MeV energies emitted from the AmBe source slow to thermal energies as a result of collisions with atomic nuclei in the formation and borehole. The slow, thermal neutrons are detected by $\mathrm{He} 3 \mathrm{Near}$ and Far detectors which are mounted on an insert which is installed from the "box" end of the drill collar (right in the figure). Events from the detectors are recorded by electronics which are also located on the same insert. Because the hydrogen located in the rock pore space is the most efficient element in slowing neutrons, the formation porosity can be inferred from the thermal neutron detection rate.

\section{Figure 5: Stabilized LithoDensity Sensor (SLD)}

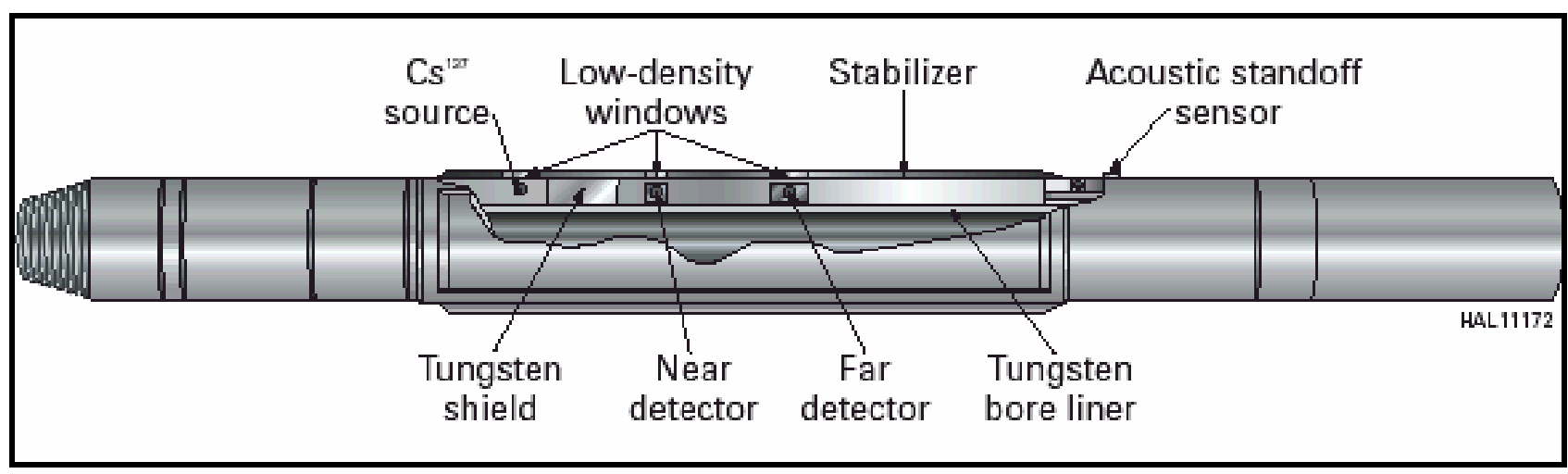

SLD. The density is determined from the scattering of gamma rays emitted by a cesium source installed in the source port. The detectors are mounted in a pressure housing that is installed in periphery of the drill collar, while the remainder of the electronics is on an insert installed in the box (right). Tungsten shields between the source and detectors - and between the detectors and the inner bore of the tool - minimize the number of gamma rays entering the detectors by paths other than through the formation. The stabilizer reduces alternative path of gamma rays through the borehole rather than through the formation. The acoustic sensor provides a measurement of the distance of the tool from the borehole wall, a measurement useful in quality control. Azimuthal sensors are located on the insert. 